\title{
A new type of chondrodystrophic mutant in the mouse
}

\author{
JANET M. FERGUSON, MARGARET E. WALLACE, AND D. R. JOHNSON
}

From the Department of Genetics, University of Cambridge, and the Department of Anatomy, University of Leeds

SUMMARY Stumpy is a new chondrodystrophic mutant in the mouse. The condition is inherited asca fully penetrant Mendelian recessive, and is not allelic with brachymorphic, achondroplasia, stubby - three similar, previously described mutants. No chromosomal position has yet been assigneid to the gene.

Phenotypically, stumpy mice are chondrodystrophic dwarfs with all cartilage-formed bones in the skeleton affected. The condition differs from the usual chondrodystrophy described in mice in that proximal elements in the limbs are affected more than distal ones.

Chondrodystrophic mutants in the house mouse have aroused interest in the past 10 years as models for these conditions in man and domestic animals. In human achondroplasia (Warkany, 1971) and Dexter cattle (Crew, 1924) the limbs are shortened to a greater degree proximally than distally. The three chondrodystrophic mutants so far studied in the mouse have limb bones shortened proximally and distally by the same amount. The present work describes a mutant 'stumpy', symbol stm (Ferguson and Wallace, 1973), which more closely resembles the condition in man and Dexter cattle in having greater proximal than distal shortening. The stump $\$ 00$ phenotype is shown in Figs. 1 and 2.

\section{Materials and methods}

GENETICS

The stumpy gene arose in the control stock of standard inbred strain $\mathrm{CBAFa} / \mathrm{Cam}$, in an experime testing the mutagenicity of two contraceptive steroids (Wallace et al., in preparation). Matings stum py $\times$ stumpy, backcrosses and intercrosses, were made up within the CB'A strain. As homozygotes d

Received for publication 1 August 1977

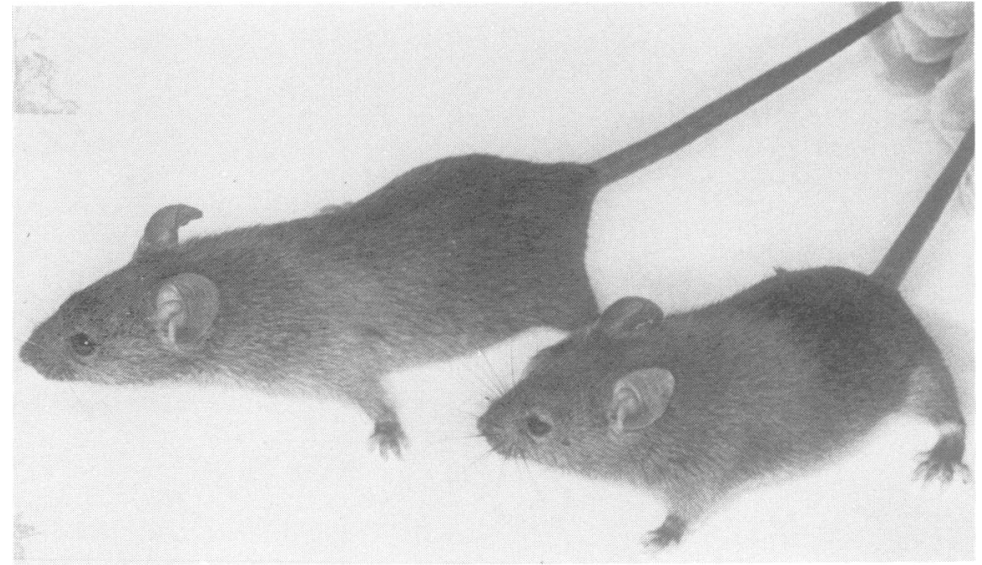

128
Fig. 1 Adult normal mouse (left) and stumpy littermate (right). 


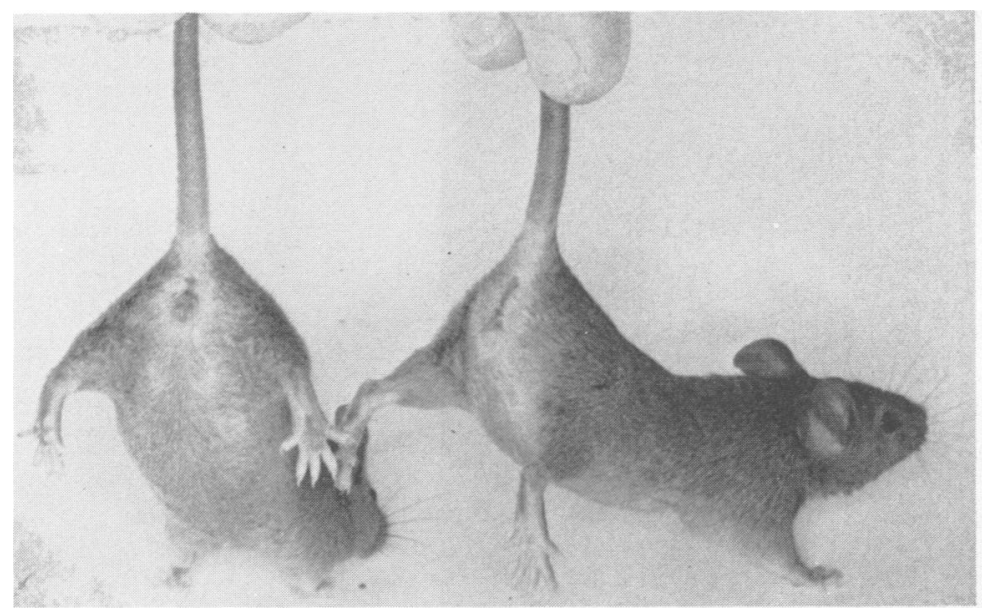

Fig. 2 Rear view of stumpy (left) and normal littermate (right).

not breed well at that stage, heterozygotes were crossed with heterozygotes of brachymorphic, $b m$, achondroplasia, $c n$, and stubby, stb, which also have breeding difficulties, and homozygous stm and $\mathrm{bm}$ were used where possible; these crosses tested allelism with the three mutants (in chromosomes 19, 4, and 2, respectively (Lane and Dickie, 1968)). Outcrosses were also made to linkage testing stocks, and multiple backcrosses made in which stm was homozygous; the markers were Danforth's short tail, $S d$, and tan-belly, $a^{t}$ (chromosome 2), brown, $b$ (chromosome 4), hammer-toe, $\mathrm{Hm}$ (chromosome 5), sombre, $e^{\text {so }}$ (chromosome 8), short-ear, se, and Maltese dilution, $d$ (chromosome 9), and twirler, $T w$ (chromosome 18). Between 80 and 400 progeny were bred for each marker tested. These backcrosses also gave data on sex-linkage and sex-limitation.

\section{MORPHOLOGY}

Papain digestions were made of $12 \mathrm{stm} / \mathrm{stm}$ and 12 normals aged 150 to 165 days, from the CBA stm stock, and alizarin clearance preparations of a further $12 \mathrm{stm} / \mathrm{stm}$ and appropriate controls aged 107 to 167 days.

Body and tail length were measured on alizarin clearance preparations by the method of Lane and Dickie (1968). Measurements of individual bones were made by placing them on millimetre-squared graph paper under a dissecting microscope.

\section{Results}

\section{GENETICS}

The matings stumpy $\times$ stumpy gave 20 progeny, all stumpy, and the outcrosses gave normal progeny only; the gene is thus a fully penetrating recessive.

The segregations from the allelism tests (given in
Ferguson and Wallace, 1973) show that stumpy is not allelic with the three earlier chondrodystrophic mutants.

The linkage tests show that stumpy is not closely linked with any of the markers tested. The closest, but insignificant, association is with $s e$ and $d$, with recombination value $43 \cdot 10 \pm 19 \cdot 90$.

The ratio normal:stumpy from backcrosses is $466: 492$. This agrees with the expected $1: 1$; thus the gene is fully viable until weaning. Post-weaning viability until the usual age when breeding stops is good.

Figures for fertility follow: an animal is deemed infertile if it has no litters or if, in stm females, the young die or are eaten soon after birth; otherwise it is deemed fertile. Of 110 females, 87 were fertile, and of 31 males, 24 were fertile. Selection for stumpy fertility after combination with brown has so far given an

Table Skull, axial skeleton, and limb bone measurements $(\mathrm{mm})$ of $12 \mathrm{stm} / \mathrm{stm}$ mice and 12 normal controls

\begin{tabular}{|c|c|c|c|c|c|}
\hline & Normal & $\mathrm{stm} / \mathrm{stm}$ & $A / N$ & $t$ & $P$ \\
\hline Skull length* & $14.5 \pm 0.28$ & $13.4 \pm 0.25$ & 0.92 & 1.57 & 0.2 \\
\hline Skull widtht & $4.9 \pm 0.26$ & $4.9 \pm 0.28$ & 1.00 & - & - \\
\hline Body length $\ddagger$ & $56.7 \pm 1.38$ & $55.1 \pm 0.96$ & 0.97 & 0.11 & NS \\
\hline Tail length & $67.5 \pm 1.29$ & $63.1 \pm 0.93$ & 0.93 & 0.38 & NS \\
\hline Scapula length & $12.1 \pm 0.23$ & $10.3 \pm 0.26$ & 0.85 & $2 \cdot 72$ & $<0.02$ \\
\hline Clavicle length & $9.2 \pm 0.26$ & $7.4 \pm 0.28$ & 0.80 & 2.56 & $<0.02$ \\
\hline Humerus length & $11.8 \pm 0.26$ & $6.9 \pm 0.28$ & 0.58 & 7.03 & $\ll 0.01$ \\
\hline Radius length & $11.4 \pm 0.26$ & $7.7 \pm 0.28$ & 0.67 & $5 \cdot 13$ & $\ll 0.01$ \\
\hline Ulna length & $13.4 \pm 0.26$ & $9.8 \pm 0.28$ & 0.73 & $5 \cdot 16$ & $\ll 0.01$ \\
\hline Pelvis length & $19.4 \pm 0.38$ & $16.8 \pm 0.12$ & 0.86 & $3 \cdot 38$ & $\ll 0.01$ \\
\hline Femur length & $15.0 \pm 0.23$ & $10.0 \pm 0.26$ & 0.66 & 7.42 & $\ll 0.01$ \\
\hline Tibia length & $17.1 \pm 0.25$ & $12.5 \pm 0.26$ & 0.73 & 7.39 & $\ll 0.01$ \\
\hline
\end{tabular}

* Posterior margin of basisphenoid to nasal spine. †Across maxillary-frontal suture.

$\ddagger$ Anterior side of atlas to second caudal vertebra.

$\$$ Second caudal vertebra to tail tip. 

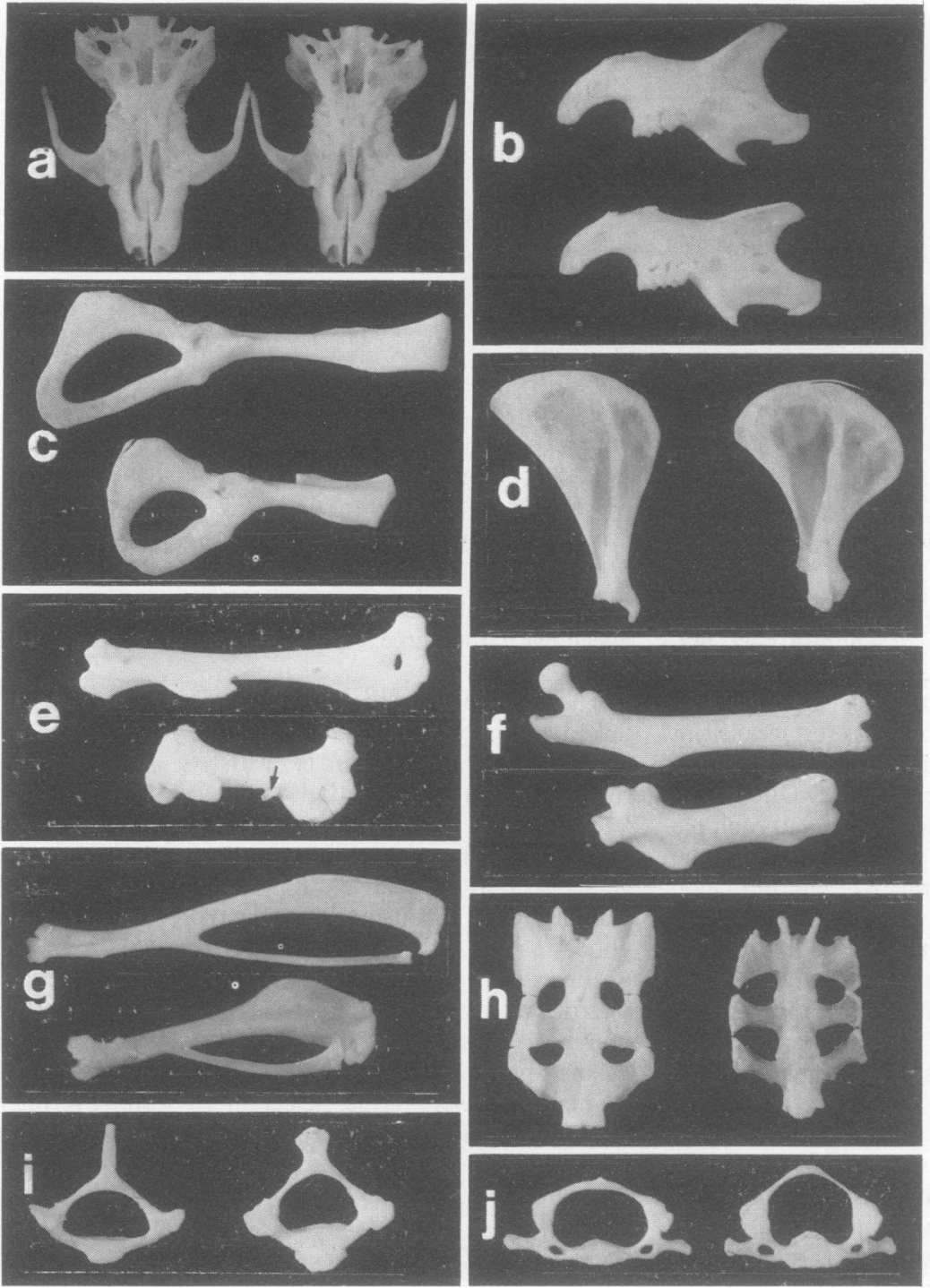

Fig. 3 (a) Normal (left) and stm/stm skull, ventral view; (b) normal (above) and stm/stm mandible, lingual aspect; $(c)$ normal (above) and stm/stm pelvis; (d) normal (left) and stm/stm scapula; (e) normal (above) and stm/stm humerus; note exostosis (arrowed) $(f)$ normal (above) and stm/stm femur; (g) normal (above) and stm/stm tibia; $(h)$ normal (left) and stm/stm sacrum; (i) normal (left) and stm/stm second thoracic vertebra; $(j)$ normal (left) and $\mathrm{stm} / \mathrm{stm}$ cervical vertebra. improvement, possibly because of slight increase in size conferred by brown (Gruneberg, 1952).

These data give no case for sex-linkage or sexlimitation.

\section{MORPHOLOGY}

Almost every bone in the stumpy skeleton differs from normal, sometimes grossly, sometimes more subtly. This is shown in Fig. 3 (a-j). Most dramatically affected are the proximal limb bones (humerus, femur) which are greatly shortened but not narrowed (Table, Fig. $3 e, f$ ). Distal limb bones are shortened a little less (Fig. $3 \mathrm{~g}$ ): limb girdles are also reduced (Figs. $3 \mathrm{c}$ and $\mathrm{d}$ ).
Points of muscle attachment (for example the deltoido tuberosity of the humerus, the trochanters of the femur, and the sacral tuberosity of the ilium) ares increased in size giving the long bones a charac- $N$ teristic, almost winged, shape. The head of the femurN is poorly developed, with little or no neck. In practice ${ }^{\omega}$ this arrangement seems to be fully functional: no dislocated hips were seen in the 12 alizarins studied.

Changes in other bones-for example, the increase in size of the vertebral bodies in a dorso-ventral plane and the remodelling of the vertebral foramina (Fig. $3 \mathrm{i}^{0} \frac{\mathrm{O}}{\circ}$ and $\mathrm{j}$ )-are less striking. Even in the vertebrae points of muscle attachment (spinous process of T2 for exam $\frac{?}{\mathrm{O}}$ 
ple) are still emphasised. Exostoses occur regularly on the shaft of the humerus and ventral aspect of the vertebral bodies (Fig. 3e, i, j).

The skull (Fig. 3a) is not significantly reduced in length, but changes can be seen in the proportions of the mandible (Fig. 3b).

\section{Discussion}

There can be no doubt that the skeletal abnormality in stumpy is systemic: all cartilaginous bones seem to be affected to a greater or lesser extent. Even the clavicle (a membrane bone) is shortened, presumably secondarily.

Throughout, the picture is of shortening combined with normal or even increased areas of muscle attachment. No doubt the enforced shortening of the muscles of the limb results in an increased diameter at rest, which gives the skinned stumpy body a particularly well-muscled appearance. Perhaps also as the mechanical advantage of the limb muscles is decreased by the proximity of origin and insertion an increase in absolute muscle mass is needed to maintain function.

As has been stated, in the mouse achondroplasias so far measured proximal and distal limb bones are shortened by a similar amount. In other conditions affecting the limbs (Ancon sheep, brachypod mouse, creeper chicken; Gruneberg, 1963), the distal extremities are more severely shortened than the proximal bones. Stumpy's resemblance to Dexter cattle and, more importantly, to human achondroplasia in having greater proximal than distal shortening makes it a unique model of veterinary and medical interest.

There is evidence both from the way in which stm grows (Johnson, 1978) and from the ultrastructural appearance of its cartilage (Johnson, 1977) that differences between stm and other chondro- dystrophics may not be trivial. In a comparison between $c n, b m$, and stm tibiae and fibulae it was found that stumpy had a sudden check at around 14 days: $c n$ and $b m$ grew slowly throughout the period of study. Ultrastructural studies of stm cartilage showed rapid growth before 14 days, followed by a failure of newly formed chondrocytes to move apart after division allied with interdigitation of cell membranes.

The simple manner of its inheritance- - a fully penetrating autosomal recessive - together with its full viability, and good fertility compared with most skeletal mutants, make for easy maintenance of a stumpy stock.

\section{References}

Crew, F. A. E. (1924). The significance of an achondroplasia-like condition met with in cattle. Proceedings of the Royal Society. Series $B, 95,228-255$.

Ferguson, J. M., and Wallace, M. E. (1973). Research news: a recessive mutant, stumpy. Mouse Newsletter, 49, 23.

Gruneberg, H. (1952). The Genetics of the Mouse, Nijhoff, The Hague.

Gruneberg, H. (1963). The Pathology of Development. Blackwell, Oxford.

Johnson, D. R. (1977). Ultrastructural observations on stumpy (stm), a new chondrodystrophic mutant in the mouse. Journal of Embryology and Experimental Morphology, 39, 279-284.

Johnson, D. R. (1978). The growth of femur and tibia in three genetically distinct chondrodystrophic mutants of the house mouse. Journal of Anatomy. (In the press.)

Lane, P. W., and Dickie, M. M. (1968). Three recessive mutations producing disproportionate dwarfing in mice. Journal of Heredity, 59, 300-308.

Warkany, J. (1971). Congenital Malformations. Year Book Medical Publishers, Chicago.

Requests for reprints to Dr Margaret E. Wallace, Department of Genetics, University of Cambridge, Downing Street, Cambridge CB2 3EH. 